\title{
Analysis Of The Enantiomers Ratio Of Citronellal From Indonesian Citronella Oil Using Enantioselective Gas Chromatography
}

\author{
Edy Cahyono ${ }^{1 *}$, Harno Dwi Pranowo ${ }^{2}$ Muchalal $^{2}$, Triyono ${ }^{2}$ \\ ${ }^{1}$ Department of Chemistry, Universitas Negeri Semarang (Unnes), Semarang, Indonesia, ${ }^{2}$ Department of Chemistry, University of Gadjah Mada, Yogyakarta, Indonesia \\ Received 19 November 2012, Revised 19 February 2013, Accepted 28 February 2013, Available online 2 March 2013
}

\begin{abstract}
Citronellal 97,3\% has been isolated from Java citronella oil (Cymbopogon winterianus) from Yogyakarta Indonesia by fractional distillation under reduced pressure $\left(5 \mathrm{cmHg}, 110-120^{\circ} \mathrm{C}\right)$. Citronellal has two optical isomerics that can be separated by capillary column of chiral GC phase. Enantioselective capillary GC with heptakis(2,3-di-O-acetyl-6-O-tert-butyldimethylsilyl)- $\beta$-cyclodextrin ( $\beta$-DEX-225) as stationary phase has been used for analysis of the enantiomers ratio of citronellal. The analysis of enantiomer ratio showed that citronellal contain of $88.21 \%$ ee of $(R)-(+)$-citronellal. Physical properties of isolated citronellal showed that the compound was (+) enantiomer. Structure identification of citronellal was carried out by GCMS, IR, and ${ }^{1} \mathrm{H}$ NMR, resulted identical fragment and spectra with standard citronellal. Theoretical study with semiempirical-AM1 method showed that energy of $(R)-(+)$-citronellal on the $\beta$-DEX 225 was lower than its $(S)-(-)$-citronellal.
\end{abstract}

| (R)-(+)-Citronellal | Fractional distillation | $\beta$-DEX 225 | Enantioselective Gas Chromatography |

® 2013 Ibnu Sina Institute. All rights reserved. http://dx.doi.org/10.11113/mjfas.v9n2.84

\section{INTRODUCTION}

Citronellal is one of monoterpenes in citronella oil. The citronellal content of high quality oil is $28-45 \%$ [1]. Citronellal has two optical isomeric with molecular weight of 154.25. Citronellal is important monoterpene aldehyde that produces some of the most intense aromas. These it become key aroma impact compounds in many essential oils (EOs). It causes the characteristic lemon-like odor. Citronellal (3,7-dimethyl-6-octenal) occurs as two enantiomers (3S)-(-)- and (3R)-(+)-citronellal. Citronellal presents at high concentrations (70-80\%) in Eucalyptus citriodora EOs (Myricaceae) and usually the main compounds in lemon balm (Melissa officinalis L. subsp. officinalis) (Lamiaceae), Lippia citriodora, citronella (Cymbopogon nardus L. Rendle-Ceylon type and Cymbopogon winterianus Jowitt - Java type) [2].

Investigations of the enantiomer ratio of citronellal have been reported in the literature. The separation of racemic citronellal isomers was done by using a $\beta$-DEX 225 column (length $30 \mathrm{~m}$, diameter $0.25 \mathrm{~mm}$, film thickness

$0.25 \mu \mathrm{m})$ with isothermal conditions at $83{ }^{\circ} \mathrm{C}$ [3]. The enantiomers ratio of citronellal in some EOs were determined by using the same column with different thermal conditions [2]. After investigating a large number of lemon balm samples they decided the enantiomer ratio of citronellal depended to some extent on its concentration in the samples. The results showed only 4 samples out of 28 genuine and 2 commercial lemon balm oils contained enantiomerically pure $(>97.7 \%)(R)-(+)$-citronellal, as reported in the literature. The most marked difference was observed for lower-concentration genuine samples, for which the $(R)-(+)$-citronellal content varied from 96.5 to 83.7\%. Citronellal in Java-type citronella oil (Cymbopogon winterianus Jowitt) could be biosynthesized either by direct conversion of geraniol to citronellal, via enol formation, or by conversion of geraniol to citronellol and then oxidation of citronellol to citronellal. Obviously, the investigation on the enantiomer distribution of some compounds in authentic and commercial citronella EOs proved that citronellal in these EOs was produced by oxidation of citronellolamounts of $(R)-(+)$-citronellal and of $(R)-(+)$-citronellol were homogeneous (means of $86.7 \%$ and $80.1 \%$ respectively) $[4,5]$.

Cyclodextrins are chiral cyclic oligomers composed of six or more D-glucose units bonded through $\alpha-(1-4)$ linkage. The cavities have different diameters dependent on the number of glucose units as showed in the Table 1 (empty diameters between anomeric oxygen atoms given in the Fig. 1). The side rim depth is the same for all three (at about $0.8 \mathrm{~nm}$ ) [6].

The $\beta$-DEX 225 capillary column is a chiral GC phase designed for separating enantiomers and other isomers. The $\beta$-DEX 225 column provides good separation of many enantiomers that are not separable or poorly separable on other chiral columns. $\beta$-Cyclodextrin consists of seven glucose residues. The mouth of the torus-shaped cyclodextrin molecule has a larger circumference than the base. Secondary hydroxyl groups at C2 and C3 atoms of the glucose units are located around the mouth. 
Table 1. The properties of main cyclodextrin [6]

\begin{tabular}{lrrrrr}
\hline Cyclodextrin & Mass & \multicolumn{2}{c}{$\begin{array}{c}\text { Outer } \\
\text { diameter }\end{array}$} & \multicolumn{2}{c}{ Cavity } \\
& & diameter & \multicolumn{2}{c}{$\begin{array}{c}\text { Solubility, } \\
(\mathrm{nm})\end{array}$} & \multicolumn{2}{c}{ Inner } & Outer & $\mathrm{g} / \mathrm{kg} \mathrm{H}_{2} \mathrm{O}$ \\
\hline$\alpha,(\text { glucose })_{6}$ & 972 & 1.52 & 0.45 & 0.53 & 129.5 \\
$\beta,(\text { glucose })_{7}$ & 1134 & 1.66 & 0.60 & 0.65 & 18.4 \\
$\gamma,(\text { glucose })_{8}$ & 1296 & 1.77 & 0.75 & 0.85 & 249.2 \\
\hline
\end{tabular}

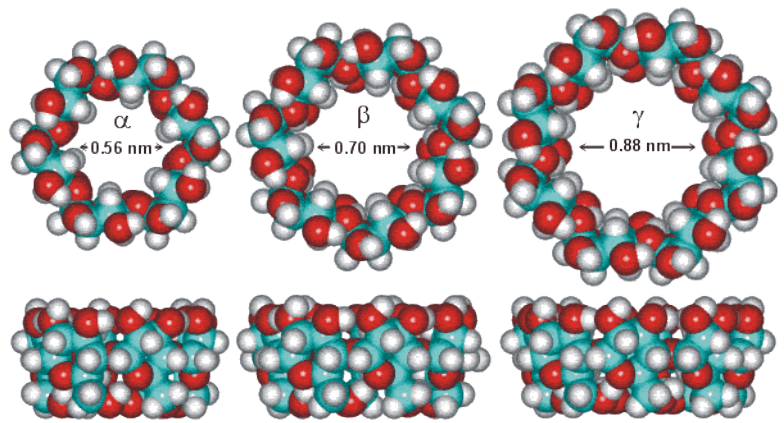

Fig. 1. The cavities of $\alpha-, \beta-$, and $\gamma$-cyclodextrin [6].

Primary hydroxyl groups at C6 atoms of the glucose units are located around the base. Heptakis(2,3-di-O-acetyl6 -O-tert-butyldimethylsilyl)- $\beta$-cyclodextrin is synthesized from native $\beta$-cyclodextrin. Primary hydroxyl groups are selectively substituted with tertbutyl dimethylsilyloxy groups. Secondary hydroxyl groups are converted into acetyl groups. Structure of $\beta$-DEX225 showed in the Fig. 2.

Many chiral derivating agents for indirect enantiomer separations on C 18 phases but also polisaccaharide, protein, donor-acceptor, ligand-exchange, crown ether and cyclodextin phase were developed [7] Gas chromatographic separations of the stereoisomers of some prochiral compound were carried out on several substituted beta-cyclodextrin columns. The stereoisomers of methylidene menthol and the corresponding tertbutyldimethylsilyl ether were separated on both the beta-CD and the heptakis(2,3,6-tri-O-methyl)-beta-cyclodextrin (TME-beta-CD) columns [8]. Separation of the diastereomers of the cardioactive and antimalarial cinchona alkaloids and of two antiestrogens was demonstrated as well [9]. In this paper we report isolation and separation of $(R)$ $(+)$-citronellal from citronella oil. Enantioselective gas chromatography with $\beta$-DEX 225 capillary column was used for separated enantiomers of citronellal.

\section{EXPERIMENTAL}

\subsection{Materials, Method and Instruments}

Citronella oil (Cymbopogon winterianus) obtained from Sari Warna Yogyakarta, and standards citronellal $(+) /(-)$-citronellal (Fluka), (+)/(-)-citronellal (E.Merck), and (R)-(+)-citronellal (Sigma Aldrich) then called as citronellal $\mathrm{A}, \mathrm{B}$, and $\mathrm{C}$ respectively.

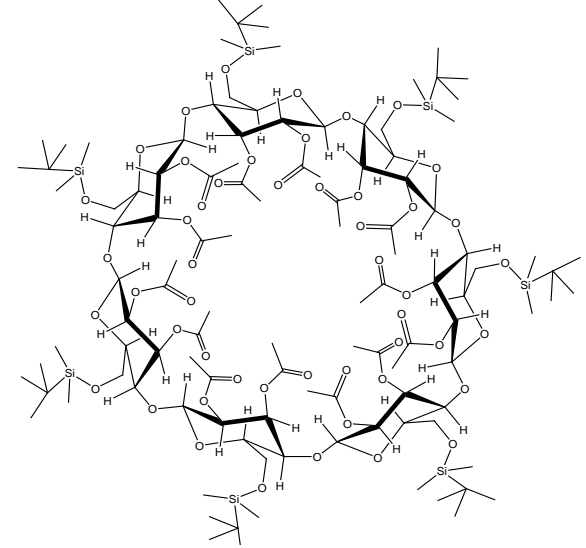

Fig. 2. Heptakis (2,3-di-O-acetyl-6-O-tert-butyl dimethylsilyl)$\beta$-cyclodextrin

A set of fractional distillation under reduced pressure was used for isolation of citronellal from citronella oil. Test of physical properties of citronella oil and citronellal isolated consist of specific rotatiton, specific gravity, and refractive index were determined by polarimeter (E Hartnak Germany 60315), calibrated picnometer, and refractometer (Atago NAR-IT) respectively.Composition of citronella oil and destillate determined by using Gas Chromatography (Hewlett Packard 5890 Series II) and Gas ChromatographyMass Spectroscopy (Shimadzu QP 5000). Structurelucidation of citronellal conducted by FTIR spectrophotometer (Shimadzu FTIR 8201 PC) and ${ }^{1}$ HNMR spectrometre (JNM PMX 50 NMR). A $30 \mathrm{~m} \times 0.25 \mathrm{~mm}$ i.d. $\times 0.25 \mu \mathrm{m}$ film thickness Supelco $\beta$-DEX 225 capillary column was used for the enantioselective gas chromatography with FID detector. This fused silica column is coated with heptakis(2,3-di-O-acetyl-6-O-tertbutyl dimethylsilyl)- $\beta$-cyclodextrin SPB20 poly (20\% diphenyl/80\% dimethylsiloxane). GC-FID analysis was performed with a Hewlett Packard HP 6890 series instrument.

\subsection{Isolation of Citronellal}

Citronellal was isolated from citronella oil that contain more than 35\% of citronellal (GC-MS) by fractional distillation under reduced pressure $(5 \mathrm{cmHg})$. To obtain higher concentration of citronellal, distillate was redistillated. Isolated citronellal was analyzed by GC,FTIR spectrophotometer, and ${ }^{1} \mathrm{H}-\mathrm{NMR}$ spectrometer. Chromatogram and spectra citronellal isolated compared to its standard citronellal.

\subsection{Enantioselective Gas Chromatography}

GC conditions were adapted from Nhu-Trang et al. method [3]: carrier gas: hydrogen, 9.25 psig, flow $1.5 \mathrm{~mL}$ $\min ^{-1}$; injector and FID temperatures $250{ }^{\circ} \mathrm{C}$. The temperature was programmed from $60{ }^{\circ} \mathrm{C}$ (held for $10 \mathrm{~min}$ ) 
at $1^{\circ} \min ^{-1}$ to $110{ }^{\circ} \mathrm{C}$ and then at $6^{\circ} \min ^{-1}$ to $175{ }^{\circ} \mathrm{C}$ which was held for $2 \mathrm{~min}$.

\subsection{Molecular Modeling}

The stabilities of citronellal enantiomers on the $\beta$ DEX-225 chiral column were evaluated by quantum mechanical calculations. Geometry of citronellal enentiomers were optimized by Semiempirical AM1 method. Because of molecule of heptakis(2,3-di-O-acetyl-6O-tert-butyldimetylsilil)- $\beta$-cyclodextrin is to large, thus optimization was done by Molecular Mechanic $\mathrm{MM}^{+}$and then followed optimization of citronellal enantiomer in the $\beta$-DEX-225 cavity structure by Semiempirical AM1 method.

\section{RESULTS \& DISCUSSION}

\subsection{Isolation of Citronellal}

The results of physical properties determination of citronella oil are followed: specific rotation $[\alpha]_{D}^{27}-2,30^{\circ}$, specific gravity $\left[\rho_{27}\right] 0,8856 \mathrm{~g} / \mathrm{cm}^{3}$, and refractive index [ $\eta^{20}$ ] 1,4684. The results of GC-MS analysis showed that citronella oil contain of $42,12 \%$ citronellal.

Fractional distillation of $250 \mathrm{~mL}$ citronella oil obtained two fractions. The amount of first fraction (80-110 $\left.{ }^{\circ} \mathrm{C}\right)$ is $18,0 \mathrm{~mL}$ distillate, and the second fraction (110-120 ${ }^{\circ} \mathrm{C}$ ) is $99.5 \mathrm{~mL}$ ditillate. Redistillation of second fraction was obtained $68.0 \mathrm{~mL}$ ditillate with higher citronellal contain $(97.30 \%)$.

The results of physical properties determination of isolated citronellal are followed: specific rotation $[\alpha]_{D}^{27}$ $+8,35^{\circ}$, specific mass $\left[\rho_{27}\right] 0,8570 \mathrm{~g} / \mathrm{mL}$, and refractive index $\left[\eta^{20}\right] 1,4478$, while physical properties of standard citronellal B are followed: $[\alpha]_{D}^{27}+3.80^{\circ},\left[\rho_{27}\right] 0.8469 \mathrm{~g} / \mathrm{cm}^{3}$, and $\left[\eta^{20}\right]$ 1.4373. Based on physical properties and spectrum data, we assumed that main contain of isolated citronellal is $(R)-(+)$-citronellal.

Structural analysis of citronellal by FTIR spectrophotometer showed the identical spectrum with IR spectrum of standard citronellal C. Figure 3 (a) showed spectrum with $v_{\max }$ : 1724,2 (s, C=O aldehyde), 2870,08 and 2715,77 (w, C-H aldehyde), 2924,09 (s, C-H sp ${ }^{3}$ ), 1643,35 (w, C=C), 1450,47 (m, $-\mathrm{CH}_{2}-$ ), 1381,03(m, $\left.-\mathrm{CH}_{3}\right)$ $\mathrm{cm}^{-1}$.

${ }^{1} \mathrm{H}$-NMR spectrum of isolated citronellal appropriate to ${ }^{1} \mathrm{H}-\mathrm{NMR}$ spectrum of standard citronellal C.

Figure 4 (a) showed spectrum (60 MHz, TMS) that consist of peak A ( $\delta=9.75 \mathrm{ppm}, \mathrm{t}, 1 \mathrm{H}$, aldehyde proton), peak $\mathrm{B}(\delta=5.08 \mathrm{ppm}, \mathrm{t}, 1 \mathrm{H}$, proton $\mathrm{C}=\mathrm{C}$ olefin), peak $\mathrm{C}$ ( $\left.\delta=2,36 \mathrm{ppm}, \mathrm{t}, 1 \mathrm{H}, \mathrm{H}_{\alpha}\right)$, peak D $(\delta=1,88-2,30 \mathrm{ppm}, \mathrm{m}, 2 \mathrm{H}$, $-\mathrm{CH}_{2}-$ bonded to $\mathrm{C}=\mathrm{C}$ olefin), peak $\mathrm{E}(\delta=1,68 \mathrm{ppm}, \mathrm{s}, 6 \mathrm{H}$, isopropylidene $=\mathrm{C}\left(\mathrm{CH}_{3}\right)_{2}$ proton), peak $\mathrm{F}(\delta=1,32 \mathrm{ppm}$, $\mathrm{m}$, $1 \mathrm{H}$, chiral $\mathrm{C}$ proton), and peak $\mathrm{G}\left(\delta=1,06 \mathrm{ppm}, \mathrm{d},-\mathrm{CH}_{3}\right.$ proton).
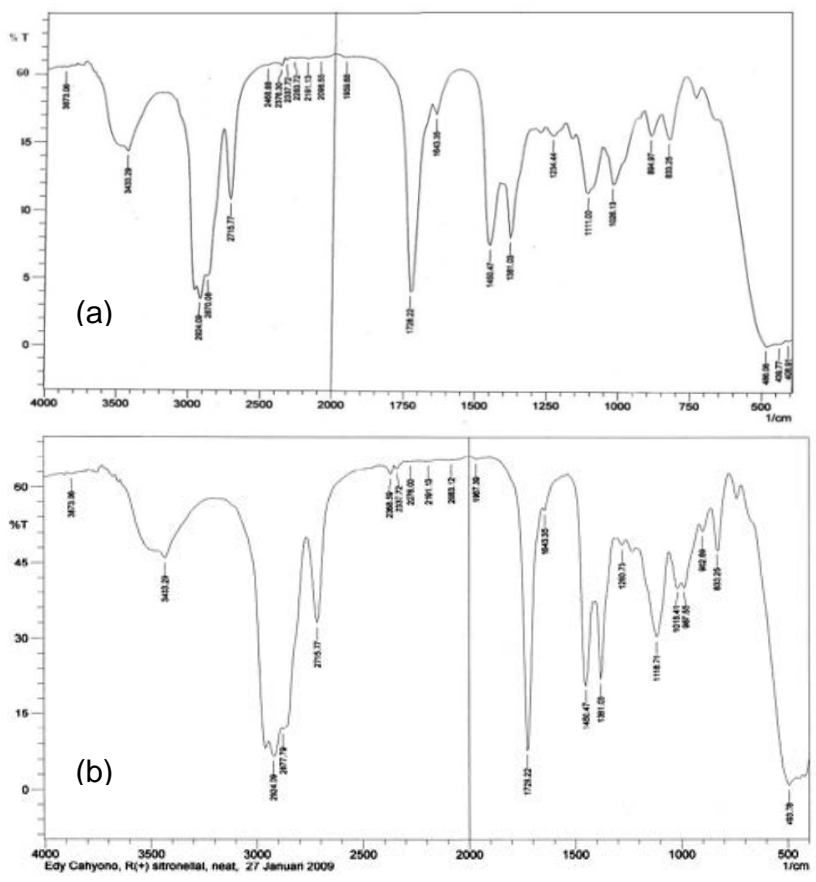

Fig. 3. FTIR spectra of (a) citronellal $97.30 \%$, and (b) standard citronellal C

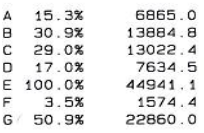

(a)

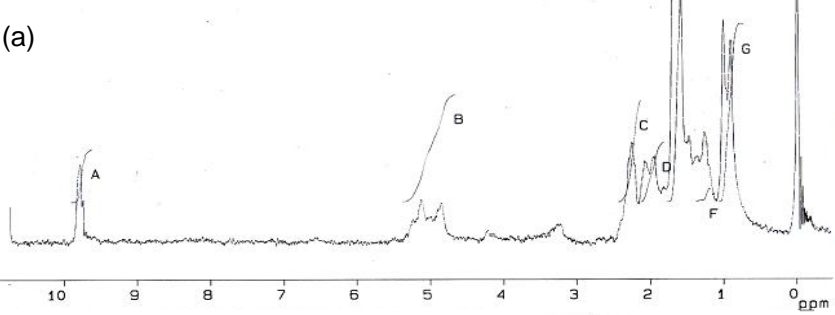

$\begin{array}{rrr}\text { A } & 15.9 x & 2434.0 \\ B & 29.8 x & 4570.9 \\ \text { C } & 19.6 x & 2998.0 \\ \text { D } & 14.4 x & 2200.6 \\ \text { E } & 47.0 \% & 7197.3 \\ F & 100.0 x & 15319.0 \\ \text { G } & 65.5 \% & 10036.0\end{array}$

(b)

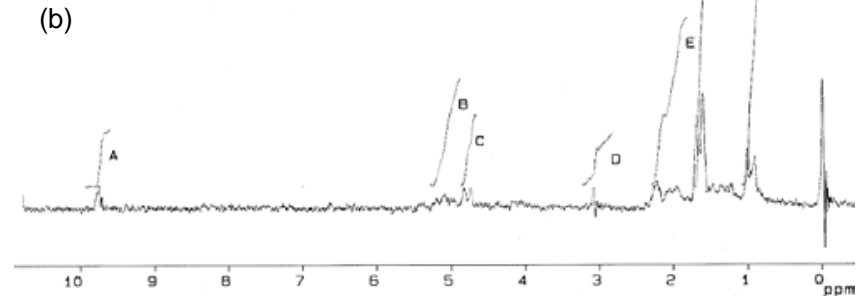

Fig. 4. Spectra ${ }^{1} \mathrm{H}$ NMR of (a) citronellal $97,30 \%$ and (b) standard citronellal $\mathrm{C}$. 


\subsection{Enantioselective Gas Chromatography}

The results of samples analysis by enantioselective gas chromatography showed in Figure 5.

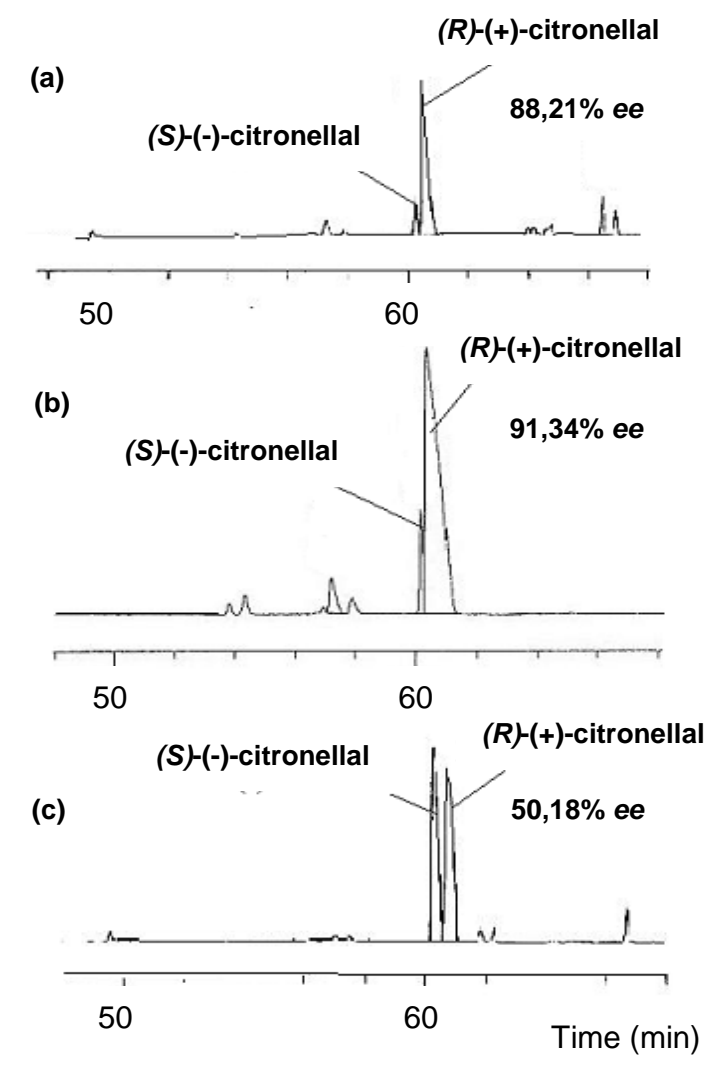

Fig. 5. Gas chromatogram in a $\beta$-DEX-225 column: (a) citronellal 97.30\%, (b) citronellal C, and (c) citronellal A.

Isolated citronellal contained $88.21 \%$ ee, commercial enantiomerically pure (standard citronellal C) contained 91.34\% ee, and commercial racemic citronellal (standard citronellal C) contained $51.18 \%$ ee of $(R)-(+)$-citronellal. The retention time of $(R)-(+)$-citronellal is longer than $(S)$ $(+)$-citronellal. It is mean that $(R)-(+)$-citronellal stronger adsorbed on the stationary phase and approximated relative boiling point of $(R)-(+)$-citronellal is higher than its enantiomer.

\subsection{Molecular Modeling}

Energy of complex $(R)-(+)$-citronellal in the $\beta$-DEX225 cavity is lower than its enantiomer (Table 2). This means that $(R)-(+)$-citronellal more stable and stronger bonded in the $\beta$-DEX-225 cavity than (S)-(-)-citronellal. The calculation results of total energy and heat formation parameters were supported the experiment data that showed the retention time of $(R)-(+)$-citronellal was longer than its enantiomer. Fig. 6 showed citronellal molecule possible to pass the $\beta$-DEX-225 cavity if its position parallel to cavity. We assumed that the enantioselectivity not only determined of polarity of citronellal enantiomer molecule but also the other parameters like geometry and volume of molecule.

Tabel 2. The results of geometry optimization (R)-(+)citronellal and (S)-(-)-citronellal in the $\beta$-DEX-225 cavity by

\begin{tabular}{clcc}
\hline No & Parameter & $\begin{array}{c}(R)-(+)- \\
\text { citronellal } \\
\text { in } \beta-D E X- \\
225\end{array}$ & $\begin{array}{c}(S)-(-)- \\
\text { citronellal } \\
\text { in } \beta \text {-DEX- } \\
225\end{array}$ \\
\hline 1 & $\begin{array}{l}\text { Total energy, } \\
\text { kkal/mol }\end{array}$ & $-42651,9144$ & $-42651,8401$ \\
2 & $\begin{array}{l}\text { Binding Energy, } \\
\text { kkal/mol }\end{array}$ & $-2770,4235$ & $-2770,4235$ \\
3 & $\begin{array}{l}\text { Heat of formation, } \\
\text { kkal/mol } \\
\text { Total dypole, } \\
\text { Debyes }\end{array}$ & $-64,2028$ & $-64,1285$ \\
& 2,646 & 2,789 \\
\hline Semiempirical-AM1 method & & \\
\hline
\end{tabular}

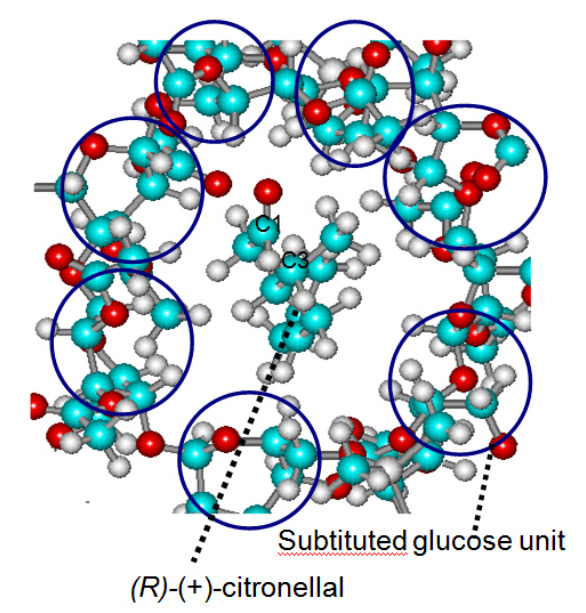

Fig. 6. Geometry structure of $(R)-(+)$-citronellal in the $\beta$ cyclodextrin cavity, optimized by Semiempirical-AM1 method.

\section{CONCLUSION}

Citronellal 97,3\% has been isolated from citronella oil (Cymbopogon winterianus-Java type) by fractional distillation under reduced pressure at $5 \mathrm{cmHg}$ and $110-120$ ${ }^{\circ} \mathrm{C}$. Enantioselective GC analysis on a Supelco $\beta$-DEX 225 column showed that citronellal contain of $88.21 \%$ ee of $(R)$ (+)-citronellal.

\section{ACKNOWLEDGEMENT}

This work is part of the activities at the Sandwich Scholarship Program that supported by DGHE of Indonesia in Catalysis Laboratory-NUS Singapore. The authors are grateful to Ass. Prof. Chuah Gaik Khuan who supervised this work and Dr. Yun Tong Nie who performed the GC analysis. 


\section{REFERENCES}

[1] E. Cahyono, Muchalal, Triyono, and H.D. Pranowo, Eksakta Jurnal Ilmu-ilmu MIPA, 2,2 (2010) 79-85.

[2] T.T. Nhu-Trang, H. Casabianca, and M.F. Greiner-Loustalot, Anal Bioanal Chem, 386 (2006) 2141-2152

[3] P.M. Arvela, N. Kumar, V. Nieminen, R. Sjöholm, T. Salmi, and D.Y. Murzin,. Journal of Catalysis, 225 (2004) 155-169

[4] P. Kreis and A. Mosandl, Flav Fragr J, 9 (1994) 249-256.
[5] A. Akhila, Phytochemistry, 25, 2(1986) 421-424

[6] M. Chaplin, Water Structure and Sciences,http://www.lsbu.ac.uk/ [27 $7^{\text {th }}$ Oct 2008]

[7] M, J. Lmmerhofer, Chromatograph. A., 1269 (2012)1-2.

[8] HF Kasai, M Tsubuki, Y. Matsumoto , M. Shirao , K. Takahashi, T. Honda , H. Ueda, Chem Pharm Bull (Tokyo). 52 (2004) 311-315.

[9] D.W. Armstrong, T.J. Ward, R.D. Armstrong, T.E. Science. 30, 232 (1986) 1132-1135. 